Motrivivência Ano XXIV, No 38, P. 202-216 Jun./2012

http://dx.doi.org/10.5007/2175-8042.2012v24n38p202

\title{
TENSÕES E CONFLITOS NA INSERÇÃO DA CAPOEIRA NAS ESCOLAS DE SÃO JOSÉ, SC: propondo uma análise objetiva e subjetiva do processo em andamento
}

\author{
Marcelo Rocha Radicchi \\ José Luiz Cirqueira Falcão²
}

\section{RESUMO}

Buscamos analisar o contexto de inserção da capoeira nas escolas municipais, empreendendo duas vertentes de análise: a primeira, relacionada ao contexto oficial e a segunda vertente de análise, a partir das observações sobre os significados das aulas de capoeira aos sujeitos participantes da realidade. $O$ trabalho baseou-se em recorte da dissertação de mestrado defendido junto ao PPGEF/UFSC no ano de 2011. Observamos a relação conflituosa entre a capoeira e a Educação Física, enquanto disciplina de vinculação desta à escola. Observamos que esta inserção está em construção, onde algumas iniciativas de professores parecem auxiliar na legitimação desta inserção.

Palavras-chave: Capoeira; Escola; Educação Física.

\section{INTRODUÇÃO: ESTABELECENDO OS LIMITES E AS POTENCIALIDADES DO ESTUDO}

O presente estudo tem como finalidade responder ao seguinte questionamento: como a capoeira se insere nas escolas em
São José, SC? Para tal, fundamentamos nossa análise com base nos dados obtidos em uma pesquisa realizada na forma de observação participante (RICHARDSON, 2010) no período compreendido entre abril e outubro do ano de 2010 em duas escolas da rede básica de ensino do referido município. Os dados

1 Professor Assistente em regime de Dedicação Exclusiva na Universidade Federal do Amazonas (UFAM), Instituto de Ciências Sociais e Educação e Zootecnia (ICSEZ), Campus do Baixo Amazonas, Parintins (AM). Mestre em Educação Física (UFSC).Contato: marcelo.radicchi@gmail.com.

2 Professor Adjunto no Curso de Educação Física da Universidade Federal de Goiás (UFG). Doutor em Educação (UFBA). Contato: joseluizfalcao@hotmail.com. 
e informações aqui discutidos constituem parte de um dos capítulos da dissertação de mestrado de um dos autores, defendida junto ao programa de Pós Graduação em Educação Física da Universidade Federal de Santa Catarina no ano de 2011.

Buscaremos aqui esclarecer dentro das limitações de nosso estudo, o espaço e inserção (objetivo e subjetivo) da capoeira nas escolas municipais de São José, SC na época em que realizamos o estudo. Não propomos uma análise conjuntural densa das relações entre capoeira-escola-mundo do trabalho, que estaria envolvida em uma aparente "institucionalização" da capoeira na realidade observada no município de São José, SC, porém, lançaremos mão, dentro do problema proposto, tentativas de compreensão sobre os aspectos conjunturais desta inserção relacionando ao contexto real e particular observado nas duas escolas pesquisadas.

\section{NOTAS INTRODUTÓRIAS: APROXIMA- ÇÕES/TENSÕES ENTRE A EDUCAÇÃO FíSICA E A CAPOEIRA}

Iniciamos considerando que a inserção da capoeira nas escolas do município de São José, SC é uma realidade presente desde algum tempo, caracterizada por conflitos próprios em níveis institucionais, sociais e políticos. Delimitamos a análise de nosso estudo em dois enfoques distintos, mas complementares, o primeiro, relacionado ao contexto oficial da inserção da capoeira nas escolas de São José, desde meados do ano de 2009 (período em que realizamos nossa pesquisa de campo) até 2010, buscando atualizar a análise com informações obtidas através de documentos que "regulam" esta relação em termos oficiais (proposta pedagógica do município e editais mais recentes de seleção para professores de capoeira). O segundo enfoque do estudo está ligado à proposta metodológica da pesquisa que resultou em dissertação de mestrado (RADICCHI, 2011), constituída de observação participante durante o ano de 2010 e que foi conduzida na realidade das aulas de capoeira ministradas um professor que acompanhamos (chamamos aqui de professor D.) em duas escolas do município. Esta segunda vertente de análise potencializa a análise oferecendo indicações das impressões e significados mais subjetivos experimentados pelos sujeitos inseridos no cotidiano do que está sendo analisado como "oficial" neste estudo. Porém, antes de prosseguirmos, será necessário elucidar a relação de tensão entre capoeira e Educação Física, enquanto eixo de análise que perpassa toda tentativa de compreensão sobre a relação de inserção da capoeira nas escolas.

Uma breve consideração sobre a tradicional - e não menos problemática - associação entre a capoeira e a área de Educação Física inicia-se pela aproximação histórica em meados da década de 1920 dos então pensadores da área de "Educação Physica", que surgia e ganhava força em terras brasileiras, com a capoeira, chegando a ser pensada (e sistematizada) como uma possível forma de "Ginástica Nacional" brasileira ${ }^{3}$ que, dentre outros

3 Uma alternativa contextualizada ao então "Método Ginástico Francês", este último, tendo sido instituído como método de Educação Física no Brasil via decreto n 14.784 de 27 de abril de 1921 e que foi estendido às escolas de ensino secundário a partir de 1931, a partir da reforma Francisco Campos, enquanto não era criado o "Método Nacional de Educação Física". 
autores e contribuições, foi sistematizada pelo professor Inezil Penna Marinho, porém não implantado oficialmente nas escolas brasileiras (FALCÃO, 2004b).

Ainda historicamente, podemos recordar que os maiores ícones, reformadores e difusores da capoeira no Brasil, Manoel dos Reis Machado, conhecido como Mestre Bimba, criador da "Luta Regional Baiana" (ou capoeira regional) e Vicente Ferreira Pastinha (Mestre Pastinha da capoeira Angola), tiveram maior ou menor aproximação com a instituição esportiva, tradicionalmente ligada à área de Educação Física, Mestre Bimba ao "oficializar" ou "embranquecer" (como insiste Frigério [1989]) a capoeira tradicional, incorporando golpes e movimentos de lutas orientais, rituais apropriados do contexto acadêmico etc. e Mestre Pastinha, no próprio entendimento de sua academia (sendo hoje uma lógica muito própria e defendida veementemente pelo sistema de Conselhos Federal e estaduais de Educação Física) como um "Centro Esportivo de Capoeira Angola", ao ver dos autores, uma possível tentativa desses grandes Mestres, em suas sabedorias de gente do povo, com muito pouca ou modesta instrução, buscarem associar à capoeira, na época relacionada às classes marginalizadas da sociedade, a uma prática que emergia positivamente no imaginário social da época (meados de 1930 a 1950 no Brasil), que era a Educação Física, ainda atrelada ao status das faculdades de Medicina, ao movimento do higienismo e na ascensão e hegemonia do esporte sobre a Educação Física no Brasil.

Após este breve digressão, o que observamos atualmente são posicionamentos diferenciados de teóricos, amantes e praticantes da capoeira sobre esta aproximação entre a capoeira e a Educação Física ser ou não benéfica (para quem?). Há os que defendem esta aproximação, não diria à Educação Física e os seus organismos regulatórios (Conselho profissional), mas em especial ao esporte, defendendo a necessidade de uma sistematização e universalização das regras, tal como ocorre no esporte, organizando-se em confederações. Há os que entendem, como os autores, que esta aproximação ao esporte restringe um entendimento mais ampliado da capoeira enquanto prática cultural histórica, e pode levar justamente a uma aproximação deletéria aos organismos de regulação profissional (Conselhos) vinculados à Educação Física (estando o esporte intrínseca e historicamente imbricado à área) e seus mecanismos de garantia de reserva de mercado, via regulamentação e normatização descabida em uma área fora de sua abrangência de regulação (práticas culturais garantidas pela Constituição Federal de livre expressão). Nesta segunda visão, retomando a temática que discutimos neste trabalho, não seria competência apenas do professor de Educação Física o trabalho com a complexidade temática (FALCÃO, 2004b) da capoeira, mas dentro de uma perspectiva interdisciplinar, todos os professores poderiam trabalhar diversos aspectos que a capoeira enquanto prática cultural de origem afro-brasileira, contextualizada histórica e socialmente, poderia oferecer à educação dos alunos, estando também em consonância com a lei no ${ }^{\circ} 10.639 / 2003$ que trata da "obrigatoriedade do ensino da história e da cultura afro-brasileira nas escolas de ensino fundamental e médio" (BRASIL, 2003).

Esta temática de aproximação/afastamento entre Educação Física (e esporte) e a capoeira é um tema bastante complexo e que, por si só, demandaria uma análise 
mais aprofundada, entendendo os diversos discursos e posicionamentos com relação a esta temática ${ }^{4}$. Ressaltamos, no entanto, dentro do que foi proposto neste trabalho, a necessidade de registrar a importância desta temática e a existência de diversos e muitas vezes divergentes (e conflituosos) pontos de vista sobre este assunto. Há uma frase no meio capoeirano que sintetiza esta complexidade ao considerar a capoeira em seu movimento que diz que "a capoeira é... sendo!", ou seja, um constante movimento (dialético) em sua "essência", sendo uma definição a priori do que ela é ou deveria ser é praticamente impossível ou irreal, sempre parcial.

\section{O CONTEXTO OFICIAL DA CAPOEIRA NAS ESCOLAS EM SÃO JOSÉ, SC: PRIMEI- RO ENFOQUE}

Iniciamos nossa análise sobre o contexto oficial desta inserção da capoeira nas escolas do município pela observação da proposta curricular para o município (SÃO JOSÉ, 2000). Na seção do documento que trata da estruturação das aulas de Educação Física, está contemplada a possibilidade de a capoeira inserir-se nesta disciplina em sua parte extracurricular, como podemos observar no trecho extraído do referido documento (SÃO JOSÉ, 2000, p. 156):
Atualmente, com a criação do ConseIho Municipal de Educação de São José, no Sistema Municipal de Ensino; Art. 37 - A disciplina de Educação Física é obrigatória dentro da grade curricular, ministrada por professores com habilitação específica em todas as séries da Educação Infantil, Ensino Fundamental e Médio, com 3 aulas semanais, quando possível em dias alternados, sendo facultativa nos cursos noturnos. Estruturada em duas partes - Educação Física Curricular e Extra-Curricular, esta segunda com projetos de extensão como: dança, capoeira, qualidade de vida e educação de jovens e adultos. [grifos nossos]

Recordando brevemente o que já foi discutido no presente texto sobre a relação de tensão entre a capoeira e a Educação Física, em especial no trabalho com a primeira nas escolas, consideramos que a proposta curricular oferece os primeiros direcionamentos sobre como deve ser pensada e trabalhada a capoeira nas escolas do município: inserida no âmbito dos "projetos educacionais" vinculados à área de Educação Física, porém entendidos em seu caráter extracurricular. Tal realidade condiz com os editais que regulamentaram o processo seletivo público no ano de 2009 para provimento de vagas no magistério municipal de caráter temporário para atuação específica como "Professor de Capoeira na Escola".

4 Sobre esta temática, conferir os artigos e textos disponíveis no site do MNCREF (Movimento Nacional contra a Regulamentação da Educação Física), inclusive com fragmentos de processos movidos na esfera judiciária contra o que chamam de "ingerência" do Conselho Federal de Educação Física (CONFEF) na área da capoeira (lutas, yôga e pilates são também frequentemente consideradas nos processos movidos). Vide: < http://mncref. sites.uol.com.br/index $2 . \mathrm{htm}>$ (site que, embora necessite atualizações, possui muitos textos e documentos importantes relativos a esta temática) e também e também < http://mncref.blogspot.com.br/> (blog do MNCREF, atualizado constantemente). Cabe também ressaltar a visão que defende a aproximação (regulação) da capoeira pelos conselhos profissionais, vide no site do Conselho Federal de Educação Física (CONFEF), o informativo $\mathrm{n}^{\circ} 1$ do ano de 2001, registrando um (controverso) curso de capoeira para "práticos" promovido pelo próprio CONFEF em parceria com alguns mestres de capoeira, vide: < http://www.confef.org.br/extra/revistaef/show. asp?id $=3432>$. Ambas as visões, antagônicas, sugerem a complexidade e caráter litigioso desta relação Educação Física (em especial o Conselho profissional) e a capoeira. 
Tratava-se do edital número 002/2009, da Secretaria Municipal de Educação da Prefeitura de São José, de 24 de Março de 2009. Entendemos a importância da análise deste edital enquanto instrumento legitimador de uma visão oficial, capaz de direcionar aspectos da formação do trabalhador (professor) de capoeira que deseja inserir-se no espaço escolar, adquirindo vínculo (diga-se, status e estabilidade) empregatício (mesmo que temporário) com a Secretaria de Educação deste município.

Em linhas gerais, o edital previa diversos cargos para o magistério na modalidade curricular e também na já referida modalidade extracurricular (SÃO JOSÉ, 2000), para os chamados "Projetos Educacionais". O vencimento em ambas as modalidades (curricular ou extracurricular) era semelhante, respeitadas a carga horária e a titulação do professor. Interessante notar que, se por um lado não havia distinção entre os vencimentos para o professor que atua em uma ou outra modalidade, cabe, no entanto, a reflexão de ser um edital para preenchimento de vagas temporárias, com todos os problemas decorrentes deste processo ${ }^{5}$ compreendido em alguns casos, como forma de precarização do trabalho docente (SAMPAIO \& MARIN, 2004; OLIVEIRA, 2004; LÜDKE \& BOING, 2004).

Se por um lado, existem professores efetivos na rede municipal de ensino de São José nas disciplinas tradicionalmente entendidas como componentes curriculares, o mesmo parece não ocorrer para os professores que atuam na modalidade extracurricular, nos "Projetos Educacionais", dentre os quais, os que atuam no ensino da capoeira nas escolas. Tal análise pode ser confirmada pelo recente edital número 09/2011, também da Secretaria Municipal de Educação da Prefeitura de São José, de 31 de outubro de 2011, onde as vagas para "professor de capoeira", inserido nos "projetos educacionais" são também para professores substitutos com validade de um ano (no caso, referente ao ano letivo de 2012), devendo o professor de capoeira (como outras modalidades e vagas contempladas no edital) submeter-se todo ano a processo seletivo simplificado para continuar suas atividades docentes junto à Secretaria de Educação do município. Tal procedimento parece ser recorrente não somente na Secretaria Municipal de Ensino pesquisada, mas também em diversas realidades municipais, com a utilização constante de processos seletivos simplificados para preenchimento de vagas do magistério por professores substitutos, que, de certa forma, ficam sujeitos às particularidades e instabilidades de um contrato de trabalho temporário (SAMPAIO \& MARIN, 2004; OLIVEIRA, 2004; LÜDKE \& BOING, 2004).

Um ponto que deve ser considerado para melhor compreensão das implicações tanto da proposta curricular do município (SÃO JOSÉ, 2000), quanto do edital mencionado, é o processo histórico da inserção da capoeira nas escolas do município. Processo complexo e muitas vezes contraditório, repleto de momentos de debate, conflito e acomodação à lógica ora dos grupos ligados à capoeira, ora do segmento da Secretaria Municipal de Educação.

5 Realidade comumente observada em algumas Secretarias Municipais, que oferecem regularmente processos para contratação de professores substitutos, protelando ao máximo a abertura de editais para provimento de vagas para o magistério com professores efetivos. 
A inserção da capoeira nas escolas do município de São José, SC, ocorre oficialmente $^{6}$ no ano de 1999 com a criação do projeto "Esporte Escolar". Em 2000, com a elaboração do documento da Proposta Curricular da Rede Municipal de São José, este projeto passa a ser entendido como parte da Educação Física extracurricular (SÃO JOSÉ, 2000). Desde sua criação, o referido projeto manteve parceria de maneira exclusiva com um determinado grupo de capoeira, tornando-se uma parceria hegemônica em termos capoeiranos, não abrindo espaço para que outros grupos, ou para que outros professores que não fossem do referido grupo, atuassem no projeto ${ }^{7}$. Tal realidade de exclusividade das aulas de capoeira na escola por um determinado grupo de capoeira é modificada, com intensa participação dos diversos grupos e associações de grupos de capoeira da região (Florianópolis, São José, Palhoça), somente em meados de 2009, com a realização de processo seletivo público para contratação de professores substitutos, conforme o edital já mencionado (Edital nº2/2009 da Secretaria Municipal de Educação de São José, SC).

O entendimento adquirido deste processo a partir de conversas com outros capoeiras, ainda no ano de 2009 e 2010, foi de que esta mudança (realização de concurso seletivo de caráter público) foi uma conquista obtida pelos integrantes do movimento organizado capoeirano de Florianópolis, SC e demais municípios vizinhos, a fim de que fosse aberta a possibilidade de outros professores de capoeira, que não pertencessem ao grupo que inicialmente já estava vinculado à Secretaria Municipal de Educação de São José (desde a criação do Projeto em 1999), pudessem inserir-se nesse Projeto Educacional e também ministrarem aulas de capoeira nas escolas. Tal conquista demonstra, além da presença na região de movimentos sociais politizados vinculados à capoeira, que está em curso uma busca por melhores condições de trabalho, segurança e apoio pelo professor de capoeira (MARTINS, 2000), quando considerada a possibilidade de vincular-se como professor (mesmo que não efetivado, mas em caráter temporário) à Secretaria Municipal de Educação de São José, SC.

Outro ponto de conflito que merece menção é a exigência de formação para efetivação no cargo de "professor de capoeira" nos "projetos educacionais", conforme o edital número 002/2009 da Secretaria Municipal de Educação de São José, SC. Consta no edital a exigência de ser "graduado com licenciatura plena em Educação Física".

À parte da confusão gerada pela Resolução número 7, de 31 de Março de 2004, da Câmara de Educação Superior do Conselho Nacional de Educação ${ }^{8}$ no que diz

6 Refiro-me ao "Planejamento Curricular para a Educação Infantil e Ensino Fundamental" elaborado pelo Setor Pedagógico da Secretaria Municipal de Educação de São José, SC (SÃO JOSÉ, 2008).

7 Coincidentemente o grupo à época denominava-se "Projeto Educacional Capoeira na Escola", hoje uma entidade de caráter público. Informações em < http://www.capoeiranaescola.org.br/>.

8 A resolução que "institui as Diretrizes Curriculares Nacionais para os cursos de graduação em Educação Física, em nível superior de graduação plena" em seu artigo $4^{\circ}$ ao tratar da área de atuação e qualificação do egresso, estabelece dois parâmetros, nos parágrafos $1^{\circ}$ e $2^{\circ}$, respectivamente, para o "graduado em Educação Física" e para o "professor da Educação Básica, licenciatura plena em Educação Física". Não fica claro se o licenciado é entendido também como graduado, segundo a resolução. Cabe lembrar que o Conselho Federal de Educação Física (CONFEF) adota as nomenclaturas licenciado e bacharel, o que gera mais confusão na interpretação desta resolução. Sobre este assunto complexo e controverso, ver Souza e Silva (2009). 
respeito à nomenclatura do egresso de um curso de Educação Física nas modalidades de licenciatura ou de "bacharelado" (entendido por essa resolução como sendo graduado [SOUZA \& SILVA, 2009]), tal exigência esbarra na tensão existente entre a visão da capoeira ligada à Educação Física (entendida não apenas como manifestação cultural, mas também como esporte ou atividade física) estando passível então de ser fiscalizada e enquadrada em uma área do conhecimento de bases acadêmico-científicas, que ainda busca definir seus limites e competências, tal como a Educação Física - e a visão da capoeira como uma manifestação cultural de origem nas camadas populares, não sendo passível de regulamentação oficial por ser de livre expressão conforme consta na Constituição Federal de 1988 (COSTA 2007; MARTINS, 2005).

Neste caso, a referida exigência expõe mais uma vez a tensão já citada e analisada entre Educação Física e capoeira. Na resolução deste conflito à época, foi estabelecido, no decorrer do concurso que, embora as provas fossem as mesmas (consistindo a seleção de prova de títulos e escrita, com questões específicas de capoeira), o fato de possuir uma formação superior em Educação Física contaria mais pontos no quesito de prova de títulos, além do vencimento recebido ser condizente com o nível de formação, ou seja, caso o candidato não possuísse nível superior, receberia um menor valor referente ao seu trabalho.

Entendendo que esta realidade de contratação de professores substitutos para a área de capoeira perdura no município de São José, propomos a analisar como está o entendimento atual quanto a esta questão de exigência mínima para o candidato, conforme o último processo seletivo para professor substituto na área, o processo seletivo simplificado, edital número 09/2011, da Secretaria Municipal de Educação de São José de 31 de outubro de 2011.

Neste edital mais recente, $\mathrm{n}^{\circ}$ 09/2011, que trata do provimento de vagas para professores substitutos, relativas ao ano letivo de 2012, consta vagas para "professor de capoeira", ainda compreendido dentro da perspectiva dos "projetos educacionais" extracurriculares. Com relação ao vencimento e exigências mínimas de formação aos candidatos à vaga de capoeira, observa-se a distinção de vencimentos, através da criação de duas categorias: habilitado (vencimento: $R \$ 1.052,40$, para $20 \mathrm{~h} / \mathrm{a}$ ) e não habilitado (vencimento: $\mathrm{R} \$ 751,80$, para 20 h/a). Compreendeu-se em um primeiro momento o critério para ser classificado como candidato apto a concorrer como habilitado "Certificado de conclusão de graduação em curso de licenciatura em Educação Física e certificado de no mínimo 40h de curso de capacitação com especialidade em Capoeira" e como não habilitado, em um primeiro momento, "Certidão de frequência a partir da $5^{\text {a }}$ fase de graduação de Licenciatura em Educação Física e certificado de no mínimo 40h de curso de capacitação em especialidade em Capoeira ou Carteira de Provisionado expedida pelo Conselho Regional de Educação Física na área de Lutas Esportivas". Tal exigência foi modificada pela movimentação dos setores organizados da capoeira que conseguiram modificar as exigências para "certificado de conclusão de graduação em curso de licenciatura em Educação Física." (candidato habilitado) e "certidão de frequência a partir da $5^{\mathrm{a}}$ fase de graduação de Licenciatura em Educação Física ou Carteira de Provisionado expedida pelo Conselho Regional de Educação Física 
na área de Lutas Esportivas." (candidato não habilitado), conforme retificação do edital de 27 de março de 2012.

Tal modificação parece sugerir uma necessidade de reordenamento das exigências do concurso à realidade contextual vivenciada pelos professores de capoeira, que desejavam participar do concurso. Podemos compreender que se por um lado seria difícil a obtenção de certificados "oficiais" de capacitação, conforme exigia inicialmente o edital $n^{\circ} 09 / 2011^{9}$, considerando o complexo e difuso meio capoeirano (não aceitando facilmente instituições agregadoras, tais como Confederações, tampouco sendo referência aceita a Universidade e sua pretensa legitimidade de conhecimentos, distante do consenso e reconhecimento por parte dos mestres mais tradicionais da capoeira) e a pouca validade que têm certificados expedidos por grupos isolados de capoeira, permanece ainda a vinculação da capoeira à área de Educação Física, seja como candidato habilitado (no caso dos professores formados em Educação Física) ou candidato não habilitado, compreendendo tanto os acadêmicos de Educação Física praticantes da capoeira, ou vice-versa (capoeiristas universitários, ou seja, já praticavam a capoeira e que decidem pelo curso de Educação Física para superar esta barreira profissional para exercer sua "arte" capoeirana), ou mesmo os chamados "profissionais provisionados", categoria criada pelo Conselho Federal de
Educação Física (CONFEF), quando de sua criação (meados de 1998), contemplando os professores "práticos" que já atuavam há um determinado tempo na área da Educação Física, mas que, porém, não tinham a formação universitária na área, realizando um curso (pago, de curta duração) junto ao CONFEF (via Conselho Regional de competência) e recebendo a permissão de atuar na área como "provisionado".

Mantendo nosso enfoque de análise ainda no edital nº 009/2011 da Secretaria Municipal de Educação de São José, SC, fica ainda evidenciada uma aproximação com a Educação Física (já mencionada na proposta curricular do município, como vimos anteriormente [SÃO JOSÉ, 2000]) nos conteúdos específicos a serem exigidos na prova teórica (uma das fases do processo de seleção) para o candidato à vaga de "professor de capoeira", onde dos 31 temas para a "avaliação escrita objetiva", somente 9 deste pontos referiam-se à capoeira, sendo o restante característico do corpo de conhecimento da área de Educação Física (aspectos biomédicos, do crescimento e desenvolvimento motor e didático-pedagógicos, basicamente). Mais uma vez, torna-se marcante o interesse oficial, por parte do município, em um perfil de professor de capoeira que participe do âmbito dos projetos escolares extracurriculares e que possua algum tipo de vínculo e identidade com a área de Educação Física e seus conhecimentos.

9 Conforme item 22.1 do anexo V do edital n 09/2011 "Não serão avaliados título de Capacitação e/ou Aperfeiçoamento, não reconhecidos pelo MEC ou CEE, ou que a instituição educacional esteja em processo de reconhecimento", posteriormente modificado o mesmo item (22.1) em 16 de novembro de 2011, conforme edital de retificação: "Serão avaliados somente os título de Capacitação e/ou Aperfeiçoamento na área da educação, devidamente registrado pelo órgão competente", o que nos faz questionar qual seria o órgão competente no controverso e complexo universo capoeirano. 
Finalizo esta breve análise do contexto "oficial" de inserção da capoeira nas escolas do município de São José, SC, evidenciando mais uma vez a relação conflituosa entre Educação Física e capoeira, quando ainda em 2009, referindo-me agora ao processo seletivo simplificado promovido por meio do edital $n^{\circ} 02 / 2009$, ao realizarmos a pesquisa de campo, tive notícias de certo mal-estar no meio capoeirano local refletindo desavenças entre as duas áreas motivadas, em especial, pela defesa dos interesses corporativos de cada uma.

Trata-se do debate que gira em torno das exigências relativas ao mundo da capoeira (neste caso, possuir determinada experiência/graduação e reconhecimento no meio capoeirano para poder ministrar aulas de capoeira) e o mundo profissional onde se deseja inserir a capoeira, a saber, a escola ${ }^{10}$. Tal debate faz transparecer a existência de uma tensão entre os conhecimentos acadêmico e popular, evidenciada quando a capoeira passa a fazer parte do sistema "oficial", ou seja, quando esta sai de sua tradicional "marginalidade" e passa a vivenciar a necessidade de vincular-se ao sistema oficial de ensino. Como agir? Tal discussão é bastante complexa e atual; não pretendemos aqui nos aprofundar, porém, somos da opinião que trabalhos semelhantes a este, problematizando e analisando propostas de inserção e do trabalho com a capoeira na escola, seja na análise de seu contexto político e inserção oficial, seja na análise e aceitação subjetiva dos sujeitos que participam do processo, são de fundamental importância para entendermos e propormos melhoras na relação entre capoeira e escola.

\section{O CONTEXTO SUBJETIVO DA CAPOEIRA NAS ESCOLAS EM SÃO JOSÉ, SC: ENFO- QUE COMPREENSIVO}

Tendo já analisado o contexto social e político (diga-se, relações de poder), com base em documentos e versões oficiais, contrapondo com nossa observação realizada no campo entre os anos de 2009 e 2010, buscaremos neste segundo enfoque de análise, descrever e analisar o funcionamento cotidiano e as impressões sobre os significados criados/construídos pelos sujeitos que fazem parte da realidade da inserção da capoeira nas escolas, neste caso, restringindo-nos ao que realizamos na pesquisa de dissertação de mestrado, ou seja, o acompanhamento das aulas de um professor em especial (professor D.) que ministrava aulas de capoeira em duas escolas municipais de ensino fundamental em São José, SC. Objetivamos uma análise mais aprofundada no cotidiano e significados da prática social que estudamos, buscando oferecer uma visão mais rica e complexa ao problema que propusemos, indo desde a conjuntura aos sujeitos que participam desta conjuntura. Iniciamos por contextualizar o projeto para melhor visualização do leitor. Nos anos de 2009 e de 2010, período em que foi realizada a pesquisa como

10 Soube, na época (em 2009), do caso de um colega capoeirista, que foi aprovado no concurso para professor de capoeira junto ao município, mas que não possuía a graduação em seu grupo necessária para ministrar aulas de capoeira. Gerou-se certa animosidade em torno da possibilidade dele assumir uma turma de capoeira sem a graduação exigida pelo grupo, evidenciando claramente os pontos de tensão e conflito capazes de "erupção" entre o "oficialmente exigido" e o "culturalmente aceito/construído". O candidato terminou por não assumir a vaga por problemas em sua inscrição. 
parte da dissertação de mestrado junto ao PPGEF/UFSC, foram realizados dois concursos públicos pela Prefeitura Municipal de São José (PMSJ) para preenchimento de vagas para "membros do Magistério em caráter temporário", constando de vagas para "Professor para Projetos Educacionais ૫ Capoeira na Escola", cujos editais já foram analisados anteriormente.

Quanto à vinculação oficial do programa da capoeira nas escolas, obtivemos no ano de 2010 a informação, segundo os gestores vinculados à Secretaria de Educação do município, de que esta iniciativa de inserção da capoeira nas escolas enquanto "Projeto Educacional" não estava apoiada em regulamentações que a efetivassem no município, tendendo mais para uma política de governo (não como política municipal), sendo passível de ser retirada enquanto iniciativa, caso assim o desejasse a gestão que estivesse em seu mandato.

A coordenadora dos Projetos Educacionais da PMSJ confirmou tal informação, colocando, entretanto, que tal iniciativa com a capoeira já possuía ampla legitimidade e aceitação junto à sociedade, "sendo pouco provável a possibilidade de não mais haver esta parceria entre a secretaria de Educação de São José e as iniciativas com capoeira". Observamos aí uma realidade bastante presente em diversas cidades e municípios brasileiros, de certa "oficialidade" com relação às iniciativas com a capoeira nas escolas; sendo a capoeira, reconhecida em seu potencial educativo, porém, pouco valorizada enquanto prática a ser efetivada como política educacional da parte da gestão de uma escola ou de um sistema de ensino (embora o próprio processo seletivo simplificado, já estudado seja uma iniciativa, de certa forma, oficial).

Em termos históricos, a capoeira insere-se como modalidade ${ }^{11}$ no "Projeto Esporte na Escola", atendendo, no ano de 2008, a aproximadamente 1500 crianças no ensino fundamental e 1000 crianças no ensino infantil. Os professores que ministraram as aulas de capoeira nas escolas do município no período observado eram concursados, trabalhando em caráter temporário (conforme edital 002/2009 já mencionado) e deveriam cumprir uma carga horária de aulas de capoeira ${ }^{12}$, podendo realizá-la em uma ou mais escolas. Os professores de capoeira eram coordenados por uma equipe composta por dois professores da Secretaria de Educação do município.

As aulas de capoeira eram oferecidas no contra turno escolar das crianças (se esta estuda pela manhã, realiza capoeira e demais atividades à tarde e vice-versa) e eram de caráter facultativo; a criança decidia participar das atividades e solicitava aos pais ou responsáveis que realizassem sua inscrição nas atividades que desejassem participar na escola. Tal realidade foi modificada com a chegada do "Programa

11 Segundo dados do "Planejamento Curricular para a Educação Infantil e Ensino Fundamental” (SÃO JOSÉ, 2008), são 13 modalidades abrangendo, no ano de 2008, 22 polos no município, totalizando aproximadamente sete mil crianças e adolescentes e dois mil adultos atendidos (estes últimos participam dos projetos de qualidade de vida e saúde). As modalidades oferecidas são: dança, capoeira, qualidade de vida e saúde, judô-educativo, karatê-educativo, futsal, futebol de campo, voleibol, handebol, basquete, tênis de mesa, natação e jiu-jitsu.

12 Consta no edital 002/2009 (já referido), que a carga horária solicitada aos professores era de 20 horas semanais. 
Mais Educação ${ }^{13 "}$, onde segundo relatos dos professores entrevistados à época (ano de 2010) alunos que a princípio não tinham interesse em participar das aulas de capoeira passaram a frequentá-la, como ações da proposta do referido Programa em promover a implantação da Educação Integral nas escolas. Uma fala do professor pesquisado (professor D.) esclarece sobre a realidade vivida nas aulas de capoeira na escola e a relação com o programa "mais Educação":

- Falta espaço; alunos que não querem fazer capoeira são obrigados [a fazer aula], e horários das aulas que acabam coincidindo com hora do recreio ou de chegada das turmas regulares, o que causa alvoroço nas aulas.

Um parêntese que abrimos rapidamente, já que nos propusemos aqui a discutirmos a inserção da capoeira na escola, trata-se basicamente da percepção demonstrada pelo professor $\mathrm{D}$. de capoeira sobre sua relação com os outros professores da escola em que trabalhava. Inicialmente, quando começamos os procedimentos de visita às escolas e participação nas aulas, este havia-nos relatado certa tensão em relação aos outros professores, especialmente ao professor de Educação Física, já que, segundo seus relatos, este considerava de certa forma, injusto os vencimentos que ambos recebiam ser o mesmo. A sensação de injustiça estava relacionada às diferenças nas condições de trabalho de um professor na modalidade curricular e um na modalidade extracurricular atuando nos "Projetos Educacionais". Segundo relatos do professor D, na visão de alguns professores, transparecia a ideia de que o professor na modalidade extracurricular "pegava um trabalho mais brando", trabalhando com menor quantidade de alunos, teoricamente mais motivados que os alunos de uma turma mais heterogênea (tendo em vista que o Projeto "Capoeira na Escola" ser de inscrição facultativa aos alunos) como geralmente encontramos em uma aula de Educação Física escolar.

Embora o professor D. tenha relatado esta realidade, nas escolas que pesquisamos, não percebemos nenhum clima de hostilidade ou diminuição da importância da capoeira com relação às outras disciplinas por parte dos outros professores ou direção das escolas. As conversas informais nos períodos de intervalos entre aulas que acompanhamos na sala dos professores com professores de outras disciplinas, mesmo na ocasião em que estivemos presente em reuniões pedagógicas nas escolas; em todas as ocasiões observadas, estas relações apresentaram-se de maneira bastante cordial e amigável.

Fica, no entanto, o relato do professor D. de que a capoeira era tida como "recompensa" pelos outros professores de uma das escolas estudadas, havendo a possibilidade de proibir a participação de um aluno que não viesse se comportando bem na escola (talvez relatando aos pais,

13 “O Programa Mais Educação foi instituído pela Portaria Interministerial n. ${ }^{\circ}$ 17/2007 e integra as ações do Plano de Desenvolvimento da Educação (PDE), como uma estratégia do Governo Federal para induzir a ampliação da jornada escolar e a organização curricular, na perspectiva da Educação Integral" (BRASIL, s/d). Destacase que é um Programa do Governo Federal destinado prioritariamente às escolas de baixo IDEB (Índice de Desenvolvimento da Educação Básica), "situadas em capitais, regiões metropolitanas e grandes cidades em territórios marcados por situações de vulnerabilidade social” (BRASIL, s/d). 
por exemplo, para que retirassem o filho da capoeira por alguns dias). Poderíamos questionar se a ideia relatada pelo professor D. seria sugestiva de certa "marginalidade" na relação da inserção da capoeira no âmbito do status escolar frente a outras disciplinas/ações/professores, o que porém, não conseguimos captar no comportamento e ações dos demais professores da escola que estudamos.

Com relação aos alunos, foi possível perceber boa participação e aceitação por parte deste no período que acompanhamos (ano de 2010). Era comum ao conversarmos com o professor D. no pátio das escolas, diversos alunos virem cumprimentá-lo, o que vem a reforçar as potencialidades educativas e aceitação da capoeira por parte dos alunos, quando bem trabalhada didática e pedagogicamente (FALCÃO, 2003).

Um fato interessante que demonstra esta empatia dos alunos pela capoeira, e paradoxalmente provável desgosto pela aula de Educação Física que vivenciavam na época, ocorreu em uma das escolas observadas, no mês de maio de 2010, quando estávamos a conversar com o professor D no período entre o intervalo de uma aula de capoeira para a próxima e, ao passarmos próximos à quadra de esportes onde acontecia a aula de Educação Física (para alunos do $1^{\circ}$ ano, turma que o professor D. ministrava aulas de capoeira pela manhã), ocorreu a seguinte cena, registrada no diário de campo:

Um fato que me chamou a atenção, que talvez sugira uma empatia dos alunos pela aula de capoeira do professor D. veio da aula de Educação Física, na quadra de esportes ao lado. A professora de Educação Física realizava uma atividade de pular corda, onde um ou dois alunos pulavam enquanto que $o$ resto da turma permanecia sentada, junto à parede, realizando a contagem dos pulos. Os que estavam sentados não sei ao certo se foi porque avistaram o professor de capoeira (que estava no intervalo das aulas, passando próximo á aula de Educação Física na quadra) contavam os pulos dados pelo aluno na corda na forma de uma cantiga utilizada pelo professor $D$. sempre no final da roda (sinalizando que estava acabando, sempre com jogos em ritmo acelerado): “- 1, capoeira!, 2, capoeira!, 3, capoeira!..." (a música vai assim até a contagem de 10, quando termina a roda). O professor D. viu e acenou aos alunos, que continuaram cantando.

Tal passagem nos instiga ao significado desta expressão espontânea por parte dos alunos que estavam sentados observando outros participarem da atividade (a meu ver, "sedentos" naquele momento por movimento e por expressarem-se corporalmente; lembrando que se tratava de alunos do $1^{\circ}$ ano), além de sugerir uma empatia com o professor D. que passava próximo à quadra (de certa forma, cumprimentando-o, "celebrando" sua passagem, ao fazer menção a um elemento que talvez gostassem de sua aula), não estariam também de certa forma expressando uma vontade de estarem realizando outra atividade que não demandasse estarem sentados, mas movimentando-se, embalados por um ritmo animado, como é o caso daquilo que experimentam em uma roda da capoeira que participam na escola?

\section{PROPONDO A CONVERGÊNCIA DOS ENFOQUES DE ANÁLISE: DO CONCRETO AO SUBJETIVO E VICE-VERSA}

Propusemos uma análise diferenciada onde partimos de uma reflexão sobre o contexto social e político relacionado a 
inserção da capoeira nas escolas municipais de São José, SC, apontando para um caráter ainda não definido e em construção, em vias de uma "oficialização", mas que porém ganha cada vez mais a identidade de aproximação à área de Educação Física e seus conhecimentos particulares. Chegamos a tais conclusões tendo por base a análise de alguns documentos oficiais relacionados à temática, cruzando-se com os dados, impressões e experiências obtidas no período de realização de pesquisa de campo, na modalidade compreensiva da observação participante, durante os anos de 2009 e 2010, em duas escolas municipais de São José que ofereciam aulas de capoeira aos alunos. Foi a partir das informações coletadas no campo que propusemos uma segunda análise partindo de outro enfoque, compreensivo, buscando compreender a realidade microssocial em seus sentidos e significados, no que diz respeito à inserção da capoeira nas escolas (observadas).

Podemos compreender que este movimento de aproximação da capoeira com a escola no município de São José, SC, é um movimento contínuo, em construção, com conflitos e interesses divergentes, mas que, porém, é uma realidade de certa forma avançada quando consideramos o restante do país, justamente pelo fato de estar em construção e tendo em vista que em muitos municípios ainda a capoeira é compreendida pelos gestores municipais ou das próprias escolas, responsáveis pela Educação, como uma manifestação marginal, ligada a aspectos negativizados da cultura afro-brasileira ${ }^{14}$. É um movimento em construção e que tende à tomada de posições de choque de interesses por parte da capoeira (e seus movimentos sociais organizados) com a área de Educação Física quando esta última adota posicionamentos corporativistas, muito característicos das ações dos conselhos profissionais.

É um movimento ainda que depende das boas iniciativas individuais de cada professor, auxiliando no fortalecimento do imaginário e a importância da capoeira no âmbito da escola, como cultura a ser ensinada e que especialmente, tem o que ensinar, seja no âmbito das práticas corporais, história, sociedade, ética, musicalidade, enfim, o rico "complexo temático capoeirano", como nos lembra Falcão (2004a).

\section{REFERÊNCIAS}

BRASIL. Presidência da República. Lei 10639/03. "(...) que torna obrigatório o ensino de História e Cultura Afrobrasileira, nos ensinos Fundamental e Médio". Brasília, 2003.

BRASIL. Ministério da Educação. Secretaria de Educação Continuada, Alfabetização e Diversidade. Programa Mais Educação: passo a passo. Brasília, DF, s/d. Acesso em: 01/10/2010. Disponível em: <http://portal.mec. gov.br/dmdocuments/passoapasso_ maiseducacao.pdf $>$

COSTA, Neuber Leite. Capoeira, trabalho e educação. Dissertação de Mestrado. Universidade Federal da Bahia. Faculdade de Educação, 2007.

14 Presentemente estamos conduzindo uma orientação de Trabalho de Conclusão de Curso que aponta para este aspecto negativizado da capoeira na percepção dos gestores de escolas e da Educação no município de Parintins, AM. 
FALCÃO, José Luiz Cirqueira. Unidade didática 2: Capoeira. In: KUNZ, E. (Org.). Didática da Educação Física 1.

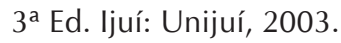

FALCÃO, José Luiz Cirqueira. O jogo da capoeira em jogo: e a construção da práxis capoeirana. Tese de Doutorado. FACED/UFBA, 2004a.

FALCÃO, José Luiz Cirqueira. Para além das metodologias prescritivas na Educação Física: a possibilidade da capoeira como complexo temático no currículo de formação profissional. Pensar a Prática. V. 7, n. 2, p. 155-170, Jul./Dez. 2004b. FRIGÉRIO, Alejandro. Capoeira: de arte negra a esporte branco. Revista Brasileira de Ciências Sociais. Rio de Janeiro, v.4, n.10, p. 85-98, Jun. 1989.

LÜDKE, Menga \& BOING, Luiz Alberto. Caminhos da profissão e da profissionalidade docentes. Educ. Soc. Campinas, v.25, n.89, p. 1159-1180, Set./Dez. 2004.

MARTINS, Marcello Fernando Bulhões. Da senzala à escola: aspectos da prática docente e o mercado de trabalho de capoeira. Conceitos. Revista da ADUFPB-JP. P. 9-15. Dezembro, 2000. MARTINS, Bruno Rodolfo. Capoeira leigo e/ou graduado: qual formação? In: ENCONTRO NACIONAL DE ESTUDANTES DE EDUCAÇÃO FÍSICA, 26. Salvador, 2005. Movimentos sociais e formação humana: da própria engrenagem, inventa a contra mola que resiste. Anais... Salvador: ExNEEF, 2005.

OLIVEIRA, Dalila Andrade. A reestruturação do trabalho docente: precarização e flexibilização. Educ. Soc., Campinas, v.25, n.89, p. 1127-1144, Set./Dez. 2004 .
RADICCHI, Marcelo Rocha. A Pre-sença da capoeira em duas escolas municipais de São José, SC. Dissertação de Mestrado. Programa de Pós-Graduação em Educação Física, Centro de Desportos. Universidade Federal de Santa Catarina, 2011.

RICHARDSON, Roberto Jarry. Pesquisa social: métodos e técnicas. $3^{\mathrm{a}} \mathrm{Ed}$. São Paulo: Atlas, 2010.

SAMPAIO, Maria das Mercês Ferreira \& MARIN, Alda Junqueira. Precarização do trabalho docente e seus efeitos sobre as práticas curriculares. Educ. Soc. Campinas, v.25, n.89, p. 1203-1225, Set./Dez. 2004.

SÃO JOSÉ. Secretaria de Educação e Cultura. Proposta curricular da Rede Municipal de Ensino de São José, SC: uma primeira síntese. São José, SC. Prefeitura Municipal de São José, SC, 2000.

SÃO JOSÉ. Secretaria Municipal de Educação. Setor Pedagógico. Planejamento Curricular para a Educação Infantil e Ensino Fundamental. São José, SC. Prefeitura Municipal de São José, SC, 2008.

SOUZA, Cláudio Lucena de; SILVA, Osni Oliveira Norberto da. Disposições legais em Educação Física: ingerências do CONFEF na tentativa de restrição profissional. Revista Digital EFDeportes. Buenos Aires, Año 14, no 135. Agosto de 2009. Acesso em: 20/08/2010. Disponível em: http://www.efdeportes.com/efd135/ disposicoes-legais-em-educacao-fisicaingerencias-do-confef.htm 
TENSIONS AND CONFLICTS IN THE INTEGRATION OF CAPOEIRA IN SCHOOLS OF SÃO JOSÉ, SC: proposing an objective and subjective analysis of the process underway

\section{ABSTRACT}

We seek to analyze the context of inclusion of capoeira in the public schools, undertaking two strands of analysis: the first related to the official context and the second strand of analysis, from observations on the meanings of capoeira classes to participants of the reality. The work was based on clipping of the dissertation defended in PPGEF/UFSC in 2011. We note the conflicting relationship between capoeira and Physical Education as a discipline that links it to the school. We found that this insertion is under construction, where initiatives of some teachers seem to help the legitimacy of this insertion.

Keywords: Capoeira; School; Physical Education.

Recebido em: fevereiro/2012

Aprovado em: junho/2012 